\title{
BAND GEEK: A STUDY OF THE TORONTO INDEPENDENT MUSIC SCENE
}

by

Sacchin Prashad

Bachelor of Arts (BA)

Ryerson University, 2017

\author{
An MRP presented to Ryerson University \\ in partial fulfillment of the requirements for the degree \\ of Master of Digital Media \\ in the Program of Digital Media
}

Toronto, Ontario, Canada, 2019

(C) Sacchin Prashad, 2019 


\section{AUTHOR'S DECLARATION}

I hereby declare that I am the sole author of this MRP. This is a true copy of the MRP, including any required final revisions.

I authorize Ryerson University to lend this MRP to other institutions or individuals for the purpose of scholarly research.

I further authorize Ryerson University to reproduce this MRP by photocopying or by other means, in total or in part, at the request of other institutions or individuals for the purpose of scholarly research.

I understand that my MRP may be made electronically available to the public.

Sacchin Prashad 


\title{
BAND GEEK: A STUDY OF THE TORONTO INDEPENDENT MUSIC SCENE
}

Master of Digital Media, 2019

Sacchin Prashad

Master of Digial Media, Ryerson University

\begin{abstract}
Digital technologies have revolutionized the music industry over the last decade and have fundamentally altered production, distribution, consumption and promotion of music. As a result, there have been fewer sales of physical recordings, less support from record companies managing musical artists and more self-promotion by musicians through social media and streaming services. My research examined how independent musicians in Toronto are handling the changed music-making scene and the challenges they face as a consequence of these changes. This paper addresses topics such as: the benefits of connecting with music audiences on social media; musicians striking licensing deals with streaming services (Spotify and Apple Music); and current strategies used to promote music online. My research findings led to my developing a new online social media page, Band Geek, that creates original documentary journalism exclusively for burgeoning local Canadian artists in the music industry.
\end{abstract}




\section{ACKNOWEDMENTS}

I would like to thank Dr. Paul Moore for his supervision and ongoing support throughout my

MRP. I would also like to thank Dr. Alya Naumova, who provided valuable feedback as a second reader.

Finally, a big thank you to my family, Elizabeth Mendl, the MDM program and all the musicians who participated in this study. 


\section{TABLE OF CONTENTS}

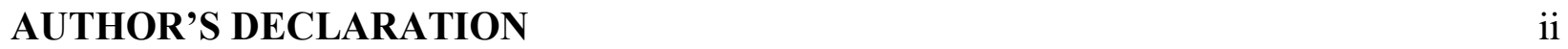

$\begin{array}{ll}\text { ABSTRACT } & \text { iii }\end{array}$

ACKNOWEDMENTS IV iv

INTRODUCTION

The Changes in Music Distribution 3

The Disappearance of the Record Label $\quad 4$

The Problem of Oversaturation $\quad 5$

Connecting with an Audience Using Social Media $\quad 6$

$\begin{array}{ll}\text { METHODS } & 7\end{array}$

$\begin{array}{ll}\text { Qualitative Research } & 8\end{array}$

$\begin{array}{ll}\text { Documentary } & 10\end{array}$

$\begin{array}{ll}\text { Journalism } & 10\end{array}$

OUTCOMES

Independent Musicians as Entrepreneurs $\quad 11$

Independent Musicians Using Streaming Services 13

Independent Musicians Using Social Media Services 15

SOLUTION: MUSIC-MAKING DOCUMENTARIES 18

Band Geek: Online Documentary Videos 18

Why Instagram? 19

An Example to Follow: BlogTO 20

$\begin{array}{ll}\text { Key Insights } & 21\end{array}$

The Genre of Band Geek's Video Format $\quad 22$

$\begin{array}{ll}\text { CONCLUSION AND NEXT STEPS } & 28\end{array}$

$\begin{array}{ll}\text { REFERENCES } & 30\end{array}$ 


\section{INTRODUCTION}

As an independent musician working in Toronto, Tom English has just started trying to find his place in a rapidly changing industry. With streaming services now the primary way people listen to music, a contract with a record label and music industry representation is no longer required to market music and reach an audience. Since April 2019, Tom has transformed his interest in writing and playing folk music into the goal of having a professional career in music. When I interviewed him in July about his efforts, he reflected on his past few months and said, "To break into the music industry today is incredibly difficult without label representation. There's an influx of independent artists and self-promotion can be incredibly difficult to attain. There's also an oversaturation of music being produced nowadays" (Prashad, personal communication, July 21, 2019). Moments later, I was surprised to learn from Tom that despite the challenges faced by independent artists breaking into the industry, musicians like him creatively engage in ways to promote, market, and present themselves in online forums. When asked about the importance of promoting his music himself, English said, "I come from a marketing background in my education. I knew that getting my music out there was more than banking on the fact that people would push themselves to listen. You have to create meaningful content that draws in the listener" (Prashad, personal communication, July 21, 2019).

Tom acknowledged that to be successful in the music industry it is not enough for his music to be of superior quality. He needed online vehicles to facilitate a breakthrough to a listening audience. He expanded this view by asserting that "social media is the ultimate way to tie in a visual experience or a communal experience to the music that people listen to, share and engage with" (Prashad, personal communication, July 21, 2019). It was this statement by Tom that made me comprehend the degree to which digital technologies are affecting independent 
musicians. I had already wanted to use social media as a creative tool to help capture the stories of independent musicians who are looking to expand their online presence in order to achieve the recognition they desire. However, it was during my interview with Tom that I came to fully appreciate just how much today's musicians already want to integrate social media into their creative process. My project, Band Geek, aims to create short documentary videos for independent musicians to circulate on social media. I knew this project could help musicians break into the music industry and increase their early exposure by the videos I would create, but I was concerned that some musicians would perceive videos as detracting from their music by putting the focus on the videos. To the contrary, the musicians I interviewed were keenly interested in my idea and perceived video content on social media as enhancing their music and bringing it to life for listeners. Band Geek helps musicians expand the story of their music and allows the audience to see behind the scenes of the creative process of music-making.

A decade ago, the only way for an independent artist to gain exposure on a large scale was to endlessly pursue major record labels and hope for a one-in-a-million recording contract opportunity. For unestablished artists it was nearly impossible to increase their fanbase beyond doing live shows (Hracs \& Leslie, 2013). Today, the emergence of new digital technologies has revolutionized the music industry and has altered and increased the production, promotion, distribution, and consumption of music. Independent musicians now operate as entrepreneurs who are responsible for the growing range of creative and non-creative tasks, including songwriting, recording, fundraising, marketing, and booking of tours (Hracs \& Leslie, 2013). The shift in the industry has resulted in fewer sales of physical recordings, less support from record company management and more self-promotion through social media and streaming services. With the emergence of new digital technologies, there has been a growing number of 
independent musicians in Canada and all around the world. According to a study conducted by MIDiA Research, a media insights and analysis firm, independent musicians are the fastest growing segment of the global recorded music business. Independent artists generated more than $\$ 643$ million in 2018, a 35\% jump from the year before (Mulligan, 2019). While technological advancements have allowed independent musicians to move forward in their careers and share their music with the world, they have also introduced new challenges for aspiring musicians who are just beginning their careers. Up-and-coming musicians must now capture the attention of listeners in an oversaturated market while simultaneously competing with established musicians

In this paper I will examine the existing problems faced by new independent musicians based on related literature research on the independent music industry. I have also conducted video interviews with four independent musicians to learn how musicians in Toronto are dealing with the problems they face. Finally, based on the examined relevant literature and interview results, this paper offers a new online social media page, Band Geek, that addresses some of the issues faced by burgeoning local Canadian artists in the music scene.

\section{The Changes in Music Distribution}

In the last three decades, music distribution experienced significant changes. These changes began with the arrival of the compact disc (CD) in 1983 that transformed the way music exists after becoming digitalized in a physical format (Alexander, 2002). Physical CD sales turned to digital sales when the iTunes Store became the first legal method of privately acquiring music digitally in 2003. The distribution of music has evolved from a traditional model based on physical formats to a model based on electronic exchanges (Vaccaro \& Cohn, 2004). More recently, music distribution has been changed significantly by streaming services which have 
altered the way music can be listened to. Streaming services started with services provided by companies such as YouTube and SoundCloud in the mid 2000's, but it was not until the launch of Spotify in 2008 that music streaming increased substantially (Richardson, 2014). With streaming services consumers now have unlimited access to millions of artists for a small monthly fee and can listen to music online on any electronic device with an Internet connection. Consumers can also download music they can listen to offline (Eiriz \& Leite, 2017). According to the Recording Industry Association of America, for the first time in 2016 music streaming services generated the majority of the American music industry's revenues, accounting for $51.4 \%$ of total industry revenues (Friedlander, 2017). This number has since increased to $75 \%$ in 2018 with music streaming now becoming the primary method of acquiring music (Friedlander, 2019). Streaming services have also opened the door for independent musicians to distribute their music.

\section{The Disappearance of the Record Label}

Traditionally, the primary method for an independent artist to create music and develop a fanbase was to have a contract based on royalties with a major record label. Record labels have the role of producing and selling albums to distributors who then make them available in stores (Eiriz \& Leite, 2017). However, with the emergence of inexpensive computers, cameras, software and equipment, musicians are able to record, edit, mix and master their own music in the convenience of their own homes (Hracs \& Leslie, 2013). This has also reduced the cost of production to the point where "creating music of a 'professional' standard is now within the reach of many independent musicians" (Haynes \& Marshall, 2017, p. 3). As a result, more independent musicians are bypassing the traditional route of working with record labels and are instead taking on the responsibilities of record label companies themselves, such as recording 
and promoting. Spotify has observed this growing trend and has taken advantage of this opportunity by striking licensing deals directly with independent musicians through Spotifyapproved distributors (Sisario, 2019). With an affordable alternative for distributing music, more and more independent musicians have started to find their way onto streaming platforms without the assistance of major record labels.

\section{The Problem of Oversaturation}

Although a number of platforms already exist for musicians to showcase their work online, the large volume of content already available on these platforms has led to difficulties that independent musicians experience in getting discovered (Lawless, 2019). With the increasing number of musicians on streaming platforms, new music is now being released in astonishingly large numbers every day. The devotion to the music of a single artist has been on a steady decline since the arrival of streaming services because "the sheer amount of choice has shifted people's expectations and consumption habits" (Lawless, 2019, para. 4). One of the ways that streaming services have been trying to address the oversaturated landscape of the music field is by creating playlists that feature a broad range of artists. This initiative is not enough "when the audience becomes fans of a compilation playlist rather than an artist's album; it leaves the artist with the short straw. Yes, there is diverse listening, but there is very little loyalty for the individual musician" (Lawless, 2019, para. 5). In order to combat the oversaturation of musicians, “it's extremely important for you to be creative in how you promote yourself” (Fox, 2019, para. 7). One of the primary ways that independent musicians are promoting themselves online is through social media. 


\section{Connecting with an Audience Using Social Media}

Social Media refers to "web-based services that allow individuals, communities, and organizations to collaborate, connect, interact, and build community by enabling them to create, co-create, modify, share, and engage with user-generated content that is easily accessible" (McCay-Peet \& Quan-Haase, 2017, p. 17). Social media platforms such as Facebook, Twitter and Instagram have become powerful tools that allow musicians to increase their presence, share high quality photos and videos that highlight their brand, and interact with their followers. Previously, musicians had to go through their agents who then had to go through press, television and radio to connect with fans. As seen in Figure 1, the emergence of social media has given musicians a direct line to consumers. Musicians can readily connect with their fans to convey a brand in a way that is easily accessible to the public. If an artist is not on social media, it is significantly more difficult for that artist to be discovered. The main challenge is that in order to create successful social media content, an artist must invest an inordinate amount of time into building his or her brand through different channels in a consistent manner (Challenges Faced By Local Independent Musicians, 2017). A common challenge that independent musicians face when getting started in their musical careers is being excessively occupied with tasks such as song-writing and recording and therefore being unable to invest sufficient time building their online brand, making it difficult for them to attract new fans and increase their following. They may also lack the necessary production skills of graphic design, photography and video production to create engaging posts that today's discerning audiences expect (Barnhart, 2018). There is no question that without social media there would be fewer independent artists in the music industry who now have the means by which to promote their work independent of large record companies. 


\section{Traditional communication}

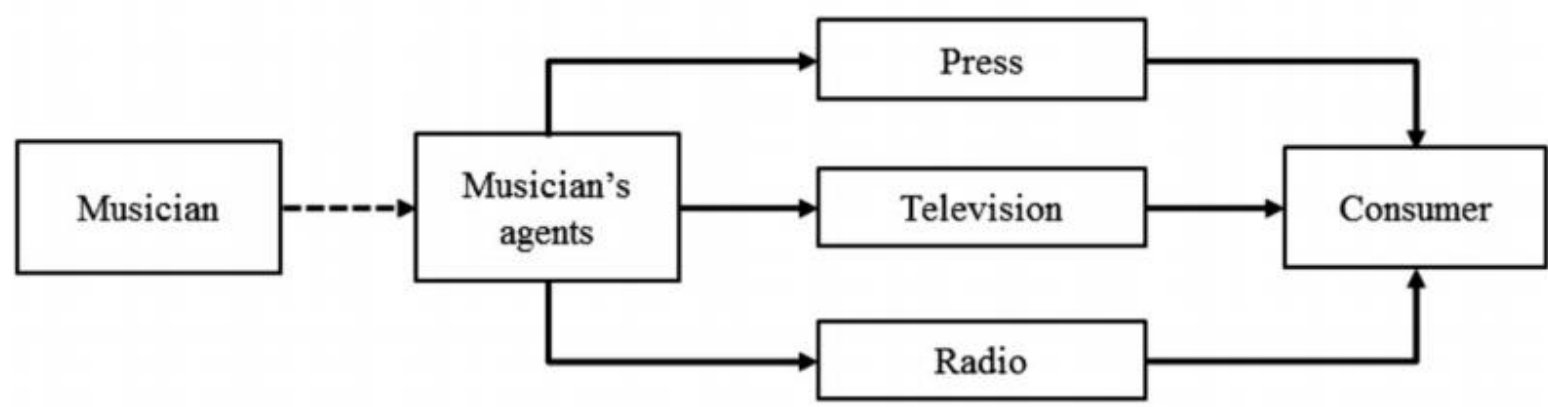

\section{Social media communication}

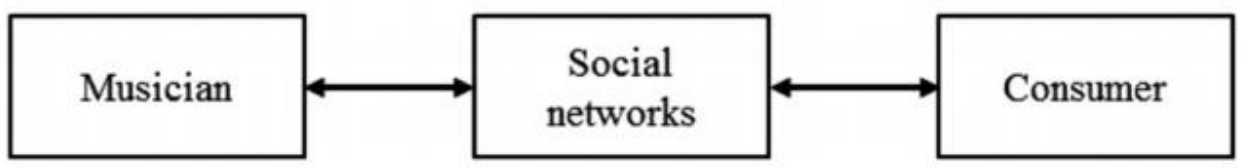

Figure 1. Communication Between Musicians and Consumers (Eiriz \& Leite, 2017, p. 887)

\section{METHODS}

The goal of my research was to understand how independent musicians are handling the changes in music distribution and what solutions they are currently applying to ameliorate the difficulties the changes present. For my proposed solution to help independent musicians promote their music I have decided to combine the elements of qualitative interviews, documentary filmmaking and video journalism. 
Qualitative Research

Due to the specificity of the research problem, I decided on a qualitative approach in my attempt to capture the different methods used by aspiring musicians to overcome the challenges they face. I chose a qualitative approach to my research in order to gain insight into how independent musicians in Toronto view, manage and resolve day-to-day obstacles they face as artists. All the interviewees who were chosen are independent musicians of different genres of music and at different points in their musical careers. Each interviewee is independent in the sense that he produces his own music and has no contract with a record label. The interviews were prepared with the aid of and supported by an interview guide (Table 1) and structured around the research objectives that were previously discussed. The questions in the interview guide were used as a means to introduce topics relevant to my research. I expected questions to arise from the responses offered to my questions; therefore, the interviews were somewhat loosely structured. I strived for spontaneity in the way I handled responses to my questions, trying throughout the interview to maintain a natural and smooth flow from one question to another.

All four interviews were done and recorded in person and transcribed to text using Microsoft Word. On average each recorded interview lasted approximately 1 hour. Despite the relatively small number of interviews conducted, the experience and knowledge of all the interviewees, as well as their diversified roles in the music industry, allowed the collection of rich data on the topics under investigation. The data collected was enough to assemble meaningful and detailed information about the current music industry, allowing for the achievement of the research objectives without further data collection. 


\section{TABLE 1: INTERVIEW GUIDE}

INTERVIEWING Independent Musicians in the Greater Toronto Area:

1. What is your name?

2. What instruments do you play?

3. What musical group are you associated with?

4. Tell me about your journey as a musician so far.

5. How do you stay motivated as a musician?

6. What have been the biggest obstacles you faced in your journey as a musician?

7. What measures, if any, have you taken to overcome these obstacles?

8. What are your ultimate goals as a musician?

9. What do you consider to be your greatest accomplishment as an independent musician?

9. How easy or difficult do you think it is to break into the music industry today?

10. Do you lose motivation when you cannot move forward?

11. What would help you feel capable of moving forward at a professional level?

12. How useful have streaming services such as Spotify and Apple Music been to you?

13. How useful have social media platforms such as Facebook, Twitter and Instagram been to you as a musician?

14. Has the emergence of social media and Spotify/Apple Music made it easier to share your work and grow your following? How so?

15. What do you think the future of the independent music industry will be in the next few years? 


\section{Documentary}

A documentary is defined as "any form of material used to communicate, document, and cover a real-life actual event, era, life story, etc. with factual accounts containing no fictional elements" (Gasana, 2013, para.1). Documentary filmmaking is unique in that it is an in-depth and informative resource which is a perfect platform to create dialogue. It serves as a powerful tool that brings important topics to the table in a captivating way that sparks conversation and sometimes even social movements. I have created three short 1-3-minute documentary video segments that feature different independent artists sharing their stories. I chose this medium because I wanted not only to write about the challenges faced by independent musicians but also to show visually the atmosphere of their working environment. I know that every musician has a unique story to tell; nonetheless, many of them face similar, if not identical challenges on the road to achieving a breakthrough in the industry. I want my documentary videos to be a resource for aspiring musicians, allowing them to learn about and from the successes and failures of other artists. I also hope these documentary videos will create more dialogue on social media about the changing music industry and the challenges faced by independent musicians.

\section{Journalism}

While documentaries tell a story and extract meaning from it, journalism, by contrast, provides only facts even when it is telling a story. By definition, journalism is "the attempt to document impartially the who, what, where, when, why, and how of a given topic, story or subject matter" (Gasanga, 2013, para 1). I decided to use journalism in addition to documentary filmmaking because I wanted to provide factual information about events related to the independent music industry. Through the use of video journalism I will be covering events such as concerts, open mics, music festivals and any other events where independent musicians can 
generally be found. The purpose of these videos is to inform independent musicians and music fans about upcoming local events where both fans and musicians can expand their network and musicians may even find opportunities to further their careers.

\section{OUTCOMES}

\section{Independent Musicians as Entrepreneurs}

The assertion that the rise of digital technologies have allowed musicians to assume several functions and roles that were previously carried out by record labels is clearly supported by the four musicians in the statements they made in the interviews. Musicians are no longer exclusively artists focused on creativity and music composition; they now operate as entrepreneurs who are responsible for the growing range of creative and non-creative tasks, including song writing, recording, fundraising, marketing, and distribution. Making music and running an entrepreneurial career are dual roles required of today's independent musicians. Wearing both hats successfully presents a challenge to independent musicians. What surprised me the most from the interviews is the number of tasks required of an independent musician, especially when the musician is a full-time student or full-time employee in an area outside the field of music.

Michael Smilovitch, an independent musician with the band Bird Problems, revealed that as independent musicians and entrepreneurs, his band members have had to acquire the skills previously required of record labels. Explaining how his band handles the problem of having limited time to focus on music, Smilovitch described how tasks get delegated among the band members. "We sort of manage everything ourselves and it's good because things sort of fell into discrete roles. One member manages the finances, one member manages the publishing and 
distribution, and one member manages the marketing and social media” (Prashad, personal communication, July 19, 2019). Immediately after this statement, Smilovitch talked about how the increased number of responsibilities, along with commitments to other areas of life, in his case a university education, make it difficult for him to find time for everything. "Of course, we all have other things going on and if we could get someone to manage and handle a lot of that stuff full time, it would lift some of the responsibilities off of us and give us more time to focus on everything else" (Prashad, personal communication, July 19, 2019). Smilovitch believes that adding a few more people to the creative team will address this issue and help his band move forward on a professional level.

Like Smilovitch, Tom English also struggles with having a full-time job and being an independent musician. When asked about his ultimate goal as a musician, English shared that he is working towards making music a full-time career. "My ultimate goal as an independent musician is to reach a level of self-sufficiency where I'm not relying on devoting 80 percent of my time working a full-time job. English went on to talk about the challenges of managing a music career and a full-time job simultaneously, saying, "Being a creative is a full-time job in itself and it's extremely difficult to devote that uneven share of time where it really just interferes with your output and productivity" (Prashad, personal communication, July 21, 2019). English believes that having a full-time music career will allow him to focus all his attention on making music and is working hard to arrive at that stage.

These responses have enlightened me that while independent musicians have more digital tools at their disposal to create, write, record and promote their work, the increased number of responsibilities, combined with personal commitments such as day jobs, introduces new challenges for them to be able to move forward in their musical journey. Being a solo artist is 
more than challenging: it is virtually impossible to manage all the roles required to be successful. Independent musicians require assistance in promoting their music or the ability to make their music a full-time career.

\section{Independent Musicians Using Streaming Services}

Streaming services have revolutionized the music industry and have given consumers instant access to millions of artists on any device. Streaming services have also opened the door for independent musicians to have their music featured to larger audiences by striking affordable licensing deals with online music distributors. With an affordable alternative for distributing music, more and more independent musicians are finding their way onto streaming platforms without the assistance of major record labels. In order to find out how beneficial these streaming services have been to independent musicians, one of my interview questions was: "How useful have streaming services such as Spotify and Apple Music been to you?" I discovered that all four musicians who were interviewed found these services have been very useful to them in various ways:

"Streaming services have definitely been helpful in putting out my content and accruing interest in my events and concerts." - Samuel Aragones (Prashad, personal communication, July 24, 2019)

"We use streaming services as much as we can to make our music as accessible as possible to anyone whatever platform or service they use." -Joseph Anidjar (Prashad, personal communication, July 19, 2019)

"With streaming services, it's definitely changed the way that you can reach an audience as an artist. You'll notice listeners from different territories in the world that you haven't really focused any effort to promote there necessarily. It's created a central playground for listeners to be introduced to new music." - Tom English (Prashad, personal communication, July 21, 2019) 
One common theme that came up in the interviews is that streaming services give independent musicians a sense of professionalism or legitimacy that previously was not available through other forms of music distribution. Both Tom English and Michael Smilovitch expressed that being on the most popular streaming platforms with musicians who are well established allows them to be recognized and acknowledged by listeners as musicians whose music is worth listening to and being taken seriously:

"Streaming services allow us to promote our music with a level of legitimacy that previously wasn't available before. It's important for musicians like myself who want to get their music out there to be taken seriously and release their music in a professional realm." -Tom English (Prashad, personal communication, July 21, 2019)

"We found that streaming services such as Spotify have been really helpful. When someone hears about the band, they always ask, 'Are you guys on Spotify?' Being on everything makes you seem more legit and more professional. There are pretty easy to use distribution services that will get you on everything for pretty cheap." -Michael Smilovitch (Prashad, personal communication, July 19, 2019)

Despite the benefits of increased exposure that streaming services give independent musicians, earnings still remain a big obstacle for those who wish to make a living from their music. A common complaint that arose in each of the interviews is that streaming services alone do not provide enough income to support musicians due to the low per-stream rates musicians receive for their streamed music. Upon further research, I discovered that 8 out of 10 musicians do not earn enough from their music to not have to worry about their financial situations because of unpredictable incomes (Mulligan, 2019). This is the predicament of the musicians I interviewed. When asked if the money made from streaming services is enough to support them, this is what two of the interviewees had to say:

"In terms of monetary compensation, it's maybe not something you can rely on in terms of making a living." -Tom English (Prashad, personal communication, July 21, 2019) 
"Since we're independent, there's no label or management taking a cut of our money. However, it still is not a large amount of money." -Joseph Anidjar (Prashad, personal communication, July 19, 2019)

These responses have revealed that streaming services have definitely assisted independent artists to create a listening audience and to make their music more accessible, as well as to reach a larger audience internationally; however, the amount of money that an independent artist earns from streaming is not enough to make a living. Independent artists must supplement their incomes by doing live performances and selling merchandise, or by working outside the music field.

\section{Independent Musicians Using Social Media Services}

Social media has given musicians the ability to connect with their consumers directly. If independent musicians want to be successful in their musical careers, they must invest a great deal of time into building their brands on a consistent basis. Because of the increase of independent musicians on online platforms, all four of the artists interviewed are taking steps to distinguish themselves from other artists on social media in order to create a personal brand to aid in establishing an online fanbase. A common response that came up in the interviews is that in today's music business model, it is no longer just about putting out good music; it is also about enhancing the music through other art forms. The independent musicians I interviewed have found success in attracting fans through a variety of social media campaigns on their personal pages.

Tom English only recently started his journey as an independent musician in April 2019. He has encountered many hurdles along the way, not the least of which is an oversaturation of independent artists producing music. He is taking small steps to stand out from other musicians online. For example, he is combining visual art with his music. When I asked him how important 
social media services have been for him, he said: "Social media builds on the auditory experience to expose an aesthetic behind the music. I use art as a tool to build on to a greater aesthetic which feeds that curiosity and really just engages the listener and creates the desire to want to listen" (Prashad, personal communication, July 21, 2019). English discussed his art projects, disclosing how learning animation for a music video helped him expand his network, saying: "My greatest achievement as an artist was the release of my animated music video for the song 'Life and Times.' It was something I was unsure that could be done as I had no prior experience with animation. I was really surprised when it all came together and received over 1000 views in the first month of its release" (Prashad, personal communication, July 21, 2019). English was happy about the validation his video received and the new fans he was able to attract after posting it on social media.

Sam Aragones, another independent musician from Toronto, Ontario, has been an independent musician for about two years. He pointed out how difficult it was for him to grow his audience at first because he was inexperienced with social media. Aragones said: "One of the biggest obstacles as a musician was establishing a fanbase outside the groups of family and friends. Connecting over social media was not my forte. When it comes to marketing yourself, this was definitely an area I was lacking in.” Aragones was able to eventually overcome this obstacle by spending more time engaging with his followers on social media through teaser videos and online contests. He continued in the interview saying: "One of the steps that I have taken in overcoming this obstacle was stepping up my social media game. This included posting more often, putting teaser videos out of some of my content and clips of me playing. Posting online contests also helped expand my fanbase and accrue interest in my shows and music" (Prashad, personal communication, July 24, 2019). Aragones went on to elucidate how being 
active on social media has not only helped grow his following but has even helped him connect and collaborate with other musicians. As a result, he has gained more opportunities to further his career. Aragones said: "Collaborating with other artists and other people in the industry is very important. One instance was connecting with someone through Instagram who was able to connect me with a producer who recorded my music and gave me opportunities to play at events. Without that, I wouldn't even know where to begin" (Prashad, personal communication, July 24, 2019).

The responses given by all four musicians have confirmed the importance social media plays in the careers of independent musicians. With the increasing number of independent artists online, musicians are taking steps to stand out among the many artists competing for recognition. Some musicians have been able to distinguish themselves by using art to enhance their music; others have increased their chances for success by offering online contests. Posting behind the scenes videos is another technique adopted by aspiring musicians to capture listening audiences. All the interviewees confirmed that social media has increased collaboration among musicians and people involved in the music industry by giving them a chance to hear each other's work and by allowing them to communicate directly with one another. 


\section{SOLUTION: MUSIC-MAKING DOCUMENTARIES}

After examining the common problems faced by independent musicians, I created a new way to help up-and-coming artists in Toronto promote their musical work online.

\section{Band Geek: Online Documentary Videos}

Band Geek is a new online documentary project dedicated to showcasing the latest and greatest in new independent Canadian music. Band Geek's purpose is to provide through Instagram a platform that gives Canadian up-and-coming artists a chance to have their music featured online and increase their audience. The goal is to make Band Geek a new space for Instagram users to discover and listen to new musicians, hear their stories and find out how they can connect with them. Instead of focusing on musicians who are already established, this page will allow new artists to take their first step towards promoting their music, to connect and to collaborate with other musicians and let listening audiences join them on their journey. Equally important are the video interviews with artists that the page provides, interviews that frequently reveal obstacles encountered by the musicians and the different methods by which some of these obstacles were overcome. These interviews are a valuable resource for artists to learn about the successes and failures of other artists. Band Geek will feature short 1 to 3 minute documentary video segments that highlight a different musician or band every week. Each video will feature an interview with the artist sharing his or her story and discussing his or her inspirations, goals, successes and challenges as an independent musician. Some of the topics that the videos will explore include: how to stay motivated as a musician; how to overcome obstacles; how to book a first gig; how to collaborate with other artists; and how to use streaming services and social media to promote musical work. The videos will also give viewers an opportunity to hear the music of the artists who are interviewed. Another feature of Band Geek will be to provide 
information about upcoming shows of artists featured on the page as well as what streaming platforms highlight their music.

In addition to information and advice, Band Geek will suggest possible solutions to problems encountered by aspiring musicians such as the ones discussed by the four musicians interviewed for the qualitative research in my thesis project. It will offer services that will allow musicians to spend more time on their music by marketing their musical endeavours, a task that takes up a significant amount of a musician's time and energy. By assuming the marketing of musical works of aspiring artists, Band Geek can alleviate the stress beginning musicians feel when they have to assume all the roles involved in launching their musical careers. The page will also solve the problem of oversaturation by being a platform that will feature local Canadian musicians exclusively, unlike the other social media pages and streaming platforms currently available that feature musical artists from all over the globe. Presently no social media page exists that deals with Canadian independent artists exclusively. Band Geek will attempt to increase collaboration among local Canadian musicians. This page will also advise viewers how to contact the artists featured in the videos, whether it is for the purpose of seeking information or advice, or in order to collaborate with the presented artists. Canadian artists can use this space to connect with people who can help them find career opportunities, such as opportunities to perform live which can definitely increase their income as well as their notoriety.

\section{Why Instagram?}

Instagram is one of the fastest-growing social networking platforms with over 1 billion active users as of June, 2018 (Newberry, 2019). Instagram is a highly visual platform that will allow me to share a wide range of content such as photos, videos, stories, and live videos. It has 
also recently launched IGTV for longer-form videos (Lua, 2019). I will be using photos to share quotes from musicians, stories to provide behind-the-scenes content from video shoots, live videos for fan engagement and IGTV for the video interviews. As a brand, Instagram also gives users the option to have an Instagram business profile which provides rich analytics for posts and the ability to schedule Instagram content (Lua, 2019). Instagram is the right platform for Band Geek to reach my target demographic which is users between the ages of 18 - 34. Instagram has become popular with the younger generation with $32 \%$ of users being between the ages of 18 and 24 and $33 \%$ between the ages of 25 and 34 (Clement, 2019). Instagram is the ideal platform for Band Geek since it allows for the sharing of pictures, videos, live videos and stories, and provides access to analytics. It also has higher usage from younger audiences. To understand how to effectively market Band Geek on Instagram, I have analyzed BlogTO, one of the top pages in Toronto and a major influence for my project.

\section{An Example to Follow: BlogTO}

$\mathrm{B} \log \mathrm{TO}$ is an online "source for local news and culture, restaurant reviews, event listings and the best of the city" (BlogTO, n.d, para.1). With over 500,000 active followers and frequent postings, BlogTO has become one of the most reliable news sources for Canadians. While I do not intend to use the exact same formula as $\mathrm{B} \log \mathrm{TO}$, I believe that it is important to look at what has made Blog TO one of the most popular pages for obtaining Toronto related news. I intend to utilize the information I gained from analyzing BlogTO when I am creating my page. BlogTO frequently posts video content on its Instagram page in order to engage with their followers. Many of these videos are sponsored posts that feature a new restaurant, store or event in Toronto. To understand why these videos have been successful for BlogTO, I have examined one of the video features from Instagram. 
The video “Tim Horton's Innovation Bar," a promotional video about Tim Horton's first ever upscale cafe, opens with a mix of interior shots and close-up food shots over upbeat music that immediately gives the viewers a sense of the restaurant's high-end atmosphere. The video then cuts to the host who gives the viewers the necessary information they need to know about the restaurant and lists some of the foods they can expect to find there. The video follows with more close-up shots of some of the foods and drinks being prepared and then cuts to several shots of popular dishes and drinks being showcased with a text description accompanying each dish. Finally, the video concludes with additional interior shots of Tim Horton's with the address of the location being displayed at the bottom. The video in total lasts 1 minute and 30 seconds (BlogTO, 2019).

\section{Key Insights}

Many of BlogTO's promotional videos follow a similar format to the video that was just described. After watching many of BlogTO's videos, I made some key observations as to why these videos are as popular as they are. BlogTO's videos are never longer than 3 minutes. This determination is most likely based on the fact that the attention span of social media users is exceedingly short. Their attention span has been significantly reduced by distracting notifications and the instant gratification users are accustomed to receiving from all the messages that ask them to engage with whatever they are watching or listening to. Video marketers are aware of this and have been tailoring content for dwindling attention spans with $56 \%$ of all videos published in 2018 being less than 2 minutes long (Chi, 2018). Another observation I made is that BlogTO combines voice with on screen text to give viewers all the necessary information they need in a consistent video format. 
Consistency helps strengthen a brand in both photos and videos. With common visual markers, the audience begins to associate a brand with a certain format and repetition helps them identify and remember a brand, nurturing familiarity, nostalgia, and recall. Visual consistency also makes viewers more likely to return to and refer others to the brand's content (Harper, 2018). Finally, I noticed that BlogTO uses eye catching shots to hook viewers into watching the video. In the Tim Horton's Innovation Bar video, the opening shots of the interior and close up food shots pique the curiosity of viewers. These observations gave me information about what makes a good Instagram video. I will implement all the information I have gleaned into the videos I will create for Band Geek. In the same way that BlogTO provides relevant news for Torontonians, I too will create a reliable music page that will keep musicians and music listeners informed about the latest news in the Toronto independent music scene.

\section{The Genre of Band Geek’s Video Format}

The main content on Band Geek will be short documentary video segments that highlight a different musician or band every week. Just like BlogTO, my videos will run between 1 to 3 minutes to accommodate the short attention span of social media users. I will also be keeping a consistent format in each video to nurture a familiarity with the format and to help viewers remember my brand. To illustrate what my video format will look like, I have broken down into segments one of the video features with Tom English that was shot and edited during the writing of this research paper. The images that are being displayed are taken directly from the shots used in my video. 


\section{Opening Shot}

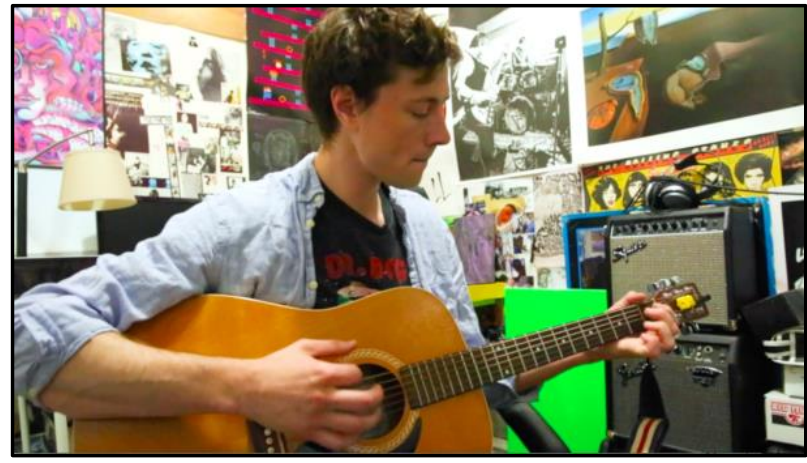

Each video begins with a shot of the featured musician playing one of his songs in his working environment. The purpose of the opening shot is for the video to quickly capture the attention of viewers just as the BlogTO videos do. This is especially important if the video is viewed as viewers scroll through their Instagram feed. Current trends in social media make establishing shots an essential part of disrupting the browsing action enabled by infinite scrolling. Current auto-play features for social media video also mean the opening seconds are crucial for a viewer deciding to pause and pay attention to any particular post. Giving viewers a sample of a musician's work may arouse their desire to continue to watch the entire video and to seek information about the artist. 


\section{Introduction Shot}

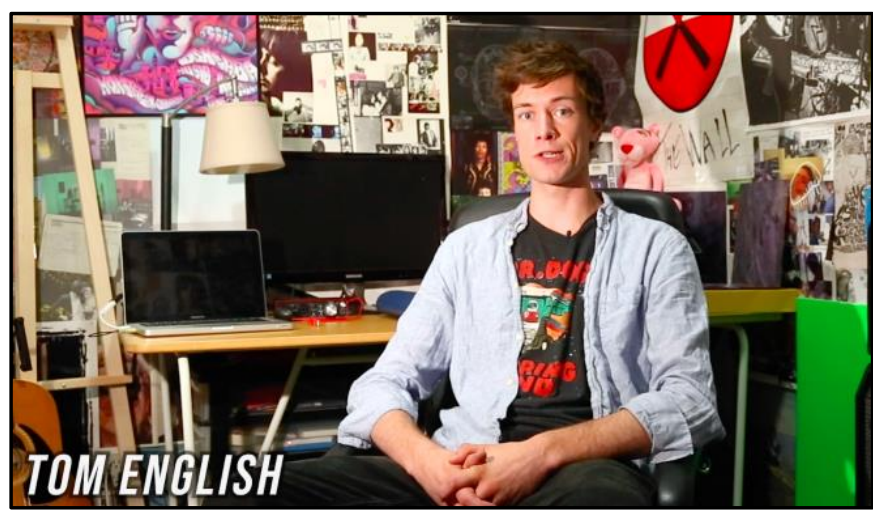

After the opening shot, the video then cuts to an interview setup with the interview subject.

Each Band Geek video will have the musicians introduce themselves, identify which music group they are associated with and list the instruments that they play. A text graphic will always be used to identify the musician. The same interview shot will appear throughout the video when the musician is answering a question with relevant b-roll being placed over the shot. These shots are important because they display the setting of the musician's everyday working environment. This will create the feeling that the viewer is being invited into the musician's workspace. 


\section{Transition Shots}
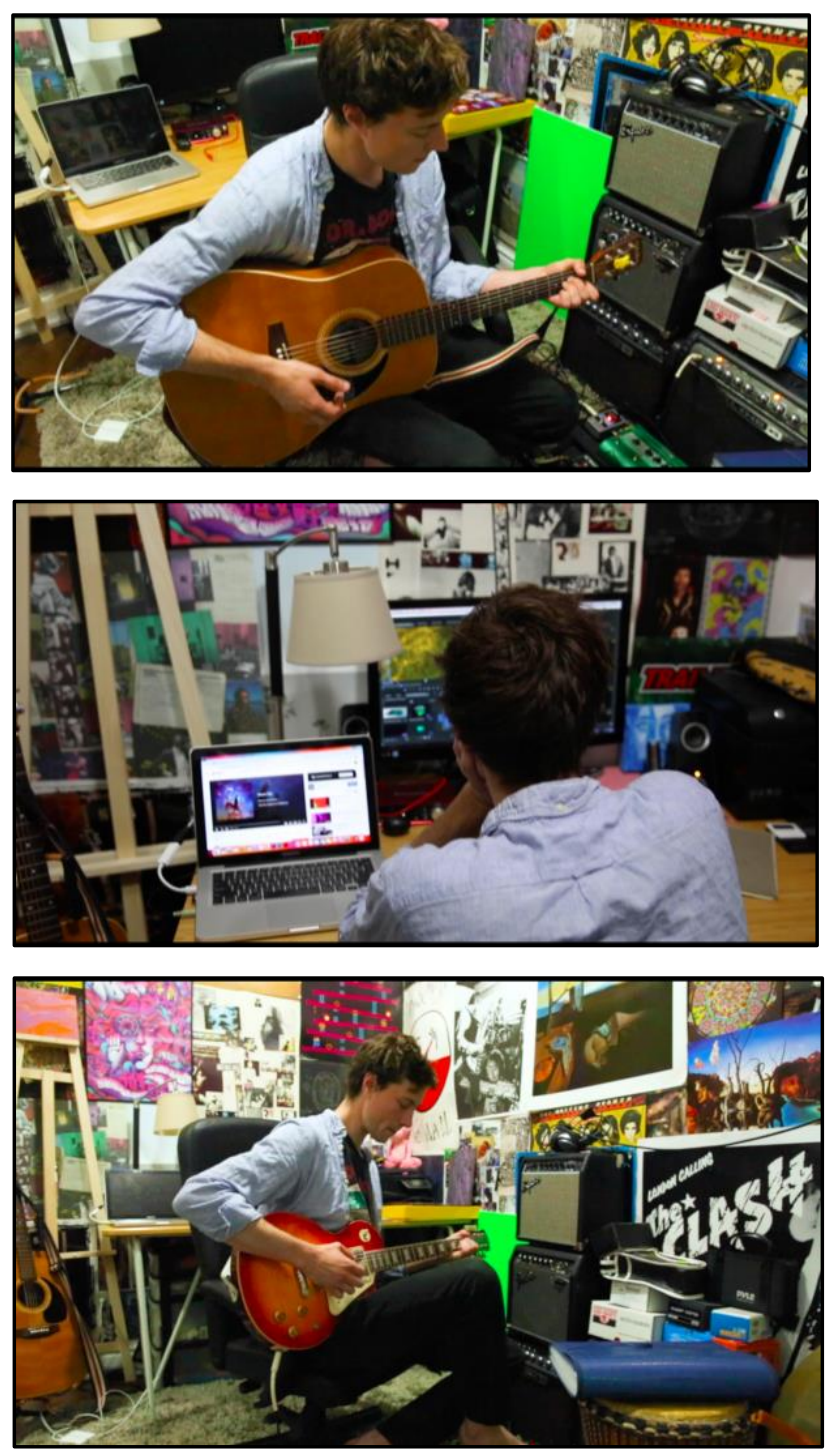

These shots are used to transition between 2 interview questions. They provide a behind the scenes experience for viewers to witness the music-making process. While the transitions obviously enable edits between different cuts from the interviews, these particular clips help complete the backstory of how the music is made and provide a sense of being behind the scenes or listening in on the musician's creative process. For Band Geek videos, transitions supplement the audience's appreciation of the creative process because the spoken interviews alone do not 
actually depict the musician playing or rehearsing music. Transitions are central to the story, especially to the soundtrack. Some of the visuals that might be included in these transition shots include an artist writing music, recording music, editing a music video, and engaging in other projects related to his or her work. Overall, the purpose of transition shots during a video is to maintain the attention of viewers.

\section{Music Feature}

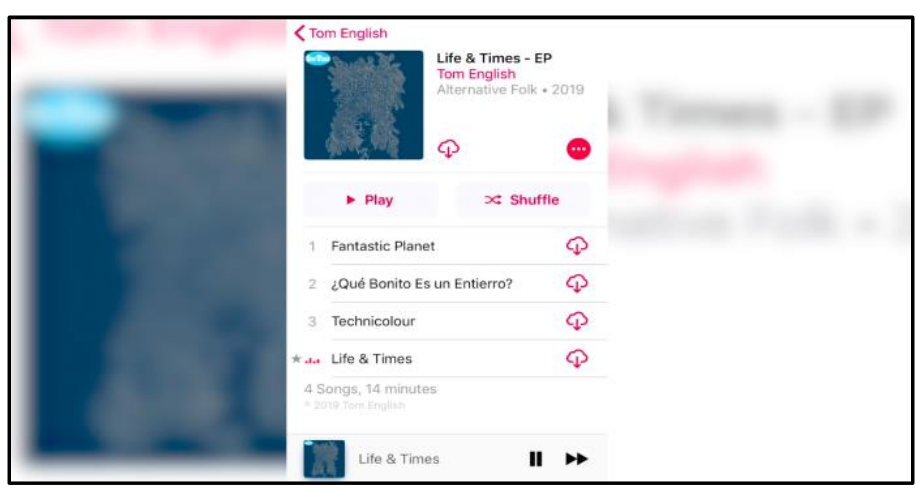

If artists currently have some of their music available on a streaming platform online, there will be a section in the video where they can discuss in detail the process involved in creating the music. The explanation will be accompanied by a visual graphic of the project the musicians are talking about. I chose to include this in the videos to give viewers a visual representation of what the project and album artwork look like so that they can find it online more easily. 


\section{How to Stay Connected}

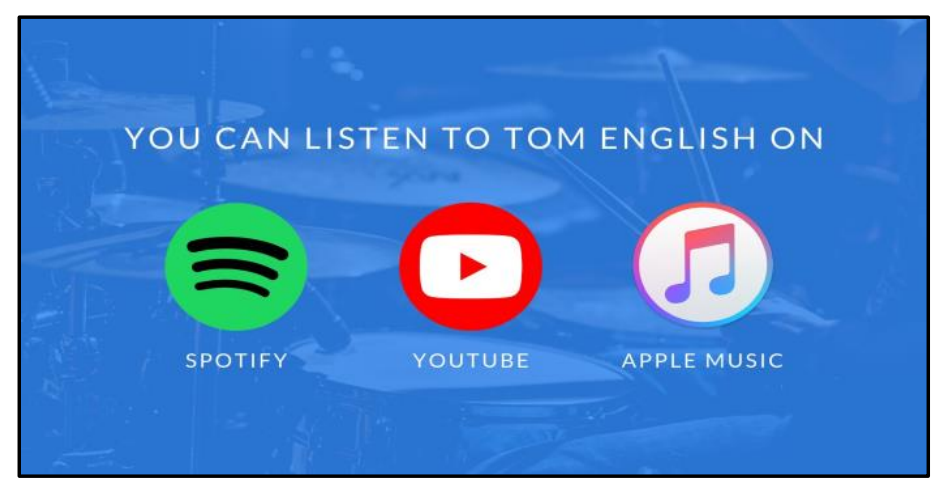

Finally, each video will end with a graphic notifying viewers which streaming platform or platforms offer music by the featured musician, providing the followers of Band Geek with the opportunity to immediately connect with the music of the artist they have just been introduced to. This feature significantly increases the chances of an artist receiving more streams, and thereby more earnings. 


\section{CONCLUSION AND NEXT STEPS}

The advent of digital technology has altered every aspect of life on the planet, including the world of music. Music is no longer produced, promoted and sold in the way it was even a decade ago. The number of independent musicians has grown exponentially since it is now possible for aspiring musical artists to bypass record labels they needed in the past to help them reach a listening audience. The relatively inexpensive cost of recording equipment and the emergence of social media and streaming services have opened the door for musicians to create, promote and share their musical work with audiences around the entire world. While it is true that the possibility of reaching a vast internet audience exists for aspiring musicians today, my research has alerted me to the number of challenges these new opportunities present. I have learned that there is a proliferation of musicians online making it exceedingly difficult for any single musician to stand out among the many artists audiences can choose from.

Independent musicians, who are now entrepreneurs, must perform all the tasks that were previously the responsibility of record labels, leaving them less time to devote to their music. Also, while streaming services provide wide exposure, the earnings gained from this source are not sufficient to provide a living for most artists who as a result are compelled to take on work outside the field of music. My research and the four interviews I conducted with local musicians attempting to gain recognition in their field confirmed for me that independent musicians could benefit from a service I have for some time contemplated providing. That service is Band Geek. Creating this service allows me to combine my passion for music with knowledge and skills I acquired through my studies at university. I am able to draw on all that I learned about video production and social media marketing. 
I look forward to interviewing and collaborating with aspiring and established musicians and keeping up with the rapidly changing music scene. I hope to continue to develop and grow as a promoter of aspiring musicians. Already I can see ways in which I could improve on the three videos I created to launch Band Geek. I would now conduct a pre-interview session with each of the artists, providing them with the questions I would be asking in the filmed interview. I would then have the opportunity to focus on only one or two topics with each artist in the filmed interview based on the answers they would provide in the pre-interview. The interviews would definitely flow more smoothly since they would be better focused, less structured and more spontaneous. I would like to conduct in-depth interviews in which I would query musicians about their online interactions with fans and inquire as to how their online relationships with other musicians and fans have helped them advance their musical careers. Prior to the interview I would review the online interactions of the musicians. Going forward I will track the musical careers of the musicians I will be interviewing. I will also assess whether Band Geek was able to help the featured artists grow in popularity, a determination I will base on whether the artists increased the number of streams and followers they have on social media. As a next step I will continue to collaborate with new musicians and create more videos. Ultimately, my goal is to see Band Geek further the careers of talented up-and-coming local independent Canadian musicians. I expect Band Geek to become a reliable music page that will keep musicians and music listeners informed about the latest news in the Toronto independent music scene. 


\section{REFERENCES}

Alexander, P. (2002). Peer-to-Peer File Sharing: The Case of the Music Recording. Review of Industrial Organization, 20, 151-161. doi: 10.1023/A:1013819218792

Barnhart, B. (2019, May 7). The Complete Guide to Social Media for Musicians. Retrieved from https://sproutsocial.com/insights/social-media-for-musicians/

BlogTO. (n.d.). Retrieved from https://www.blogto.com/jobs

BlogTO [@blogTO]. (2019, July 23). Time Hortons Innovation Bar [Instagram video]. Retrieved from https://www.instagram.com/tv/B0Qk5M3Fgoq/?igshid=3peqq0n50mvq

Chi, C. (2018, April 18). How Long Should Your Videos Be? Ideal Lengths for Facebook, Instagram, Twitter, and YouTube . Retrieved from https://blog.hubspot.com/marketing/ how-long-should-videos-be-on-instagram-twitter-facebook-youtube

Clement, J. (2019, August 9). Instagram: Age Distribution of Global Audiences 2019. Retrieved from https://www.statista.com/statistics/325587/instagram-global-age-group/

Eiriz, V. P., \& Leite, F. P. (2017). The Digital Distribution of Music and Impact on the Business Models of Independent Musicians. The Service Industries Journal, 37(13-14), 875-895. doi: 10.1080/02642069.2017.1361935

Fox, M. (2019, February 13). How To Make It In The Music Industry. Retrieved from https://www.forbes.com/sites/meimeifox/2019/02/13/how-to-make-it-in-the-music industry/\#396d01ad1a65

Friedlander, J. (2017, March 30). 2016 RIAA Shipment and Revenue Statistics. Retrieved from https://www.riaa.com/reports/news-notes-2016-riaa-shipment-revenue-statistics/

Friedlander, J. (2019, February). RIAA 2018 Year-End Music Industry Report. Retrieved from https://www.riaa.com/wp-content/uploads/2019/02/RIAA-2018-Year-End-Music Industry-Revenue-Report.pdf

Gasana, A. (2013, October 19). Documentary Filmmaking VS. Journalism. Retrieved from https://www.adelingasanafilms.com/documentary-filmmaking-vs-journalism/

Harper, A. (2019, June 27). How to Create Visual Consistency Across Video Posts. Retrieved from https://www.kapwing.com/resources/how-to-create-visual-consistency acrossvideo-posts 
Haynes, J., \& Marshall, L. (2017). Beats and Tweets: Social Media in the Careers of Independent Musicians. New Media \&amp; Society , 20(5), 1973-1993. doi:

https://doi.org/10.1177/1461444817711404

Hracs, B. J., \& Leslie, D. (2013). Aesthetic Labour in Creative Industries: The Case of Independent Musicians in Toronto, Canada. Royal Geographical Society, 46(1), 66-73. doi: https://doi.org/10.1111/area.12062

Lawless, L. (2019, March 6). Over saturation of singers on streaming sites. Retrieved from https://www.thecollegeview.com/2019/03/06/streaming-saturation/

(2017, July 2). Challenges Faced by Local Independent Musicians in Marketing Their Music. Retrieved from https://medium.com/@VirraMarketing/challenges-faced-by-localindependent-musicians-in-marketing-their-music-f8bf7610e08a

McCay-Peet, L., \& Quan-Haase, A. (2017). Chapter 2: What is Social Media and What Questions Can Social Media Research Help Us Answer? In The SAGE Handbook of Social Media Research Methods. doi: http://dx.doi.org/10.4135/9781473983847.n2

Mulligan, M. (2019, July 9). Independent Artists | The Age of Empowerment. Retrieved from https://www.midiaresearch.com/downloads/independent-artists-age-empowerment/

Newberry, C. (2019, March 5). 130+ Social Media Statistics that Matter to Marketers in 2019. Retrieved from https://blog.hootsuite.com/social-media-statistics-for-social-mediamanagers/

Richardson, J. H. (2014). The Spotify Paradox: How the Creation of a Compulsory License Scheme for Streaming On-Demand Music Platforms Can Save the Music Industry. UCLA Entertainment Law Review, 22,(1). Retrieved from https://escholarship.org/uc/item/7n4322vm

Sisario, B. (2018, September 6). A New Spotify Initiative Makes the Big Record Labels Nervous. Retrieved from https://www.nytimes.com/2018/09/06/business/media/spotify music-industry-record-labels.html

Vaccaro, V. L., \& Cohn, D. Y. (2004). The Evolution of Business Models and Marketing Strategies in the Music Industry. International Journal on Media Management, 6(1-2), 46-58. doi: 10.1080/14241277.2004.9669381 